\title{
In Search of a Conceptual Framework for the Capacities of University ITEM
}

\author{
Ronald Bisaso \\ Higher Education Group, University of Tampere, Finland \\ ronald.bisaso@uta.fi
}

\begin{abstract}
The purpose of this paper is to conceptualize and illuminate the capacities of information technology for educational management (ITEM) as a regulative element in the managerial operations of universities. It is argued that the environment in which institutional management functions has become more unpredictable typified by numerous stakeholders with various demands. Moreover, the academic organization comprises disciplinary units that respond to the stakeholders differently. However, pressures for efficiency and effectiveness are calling for more integrated functioning. We envisage that ITEM has the capacity to support internal integration of the university and also link it to external constituencies. But understanding this capacity in terms of organizational theory has been largely elusive. It is this dimension that this article seeks to elucidate by applying the tenets of the organizational learning framework to illustrate the possibilities university ITEM in integrating the functions of middle management within a university.
\end{abstract}

Keywords: University ITEM systems, organizational learning, integration.

\section{Introduction}

Concerns for the efficiency and effectiveness of institutional management are not new. There are increasing demands for efficiency and effectiveness as the universities operate in their turbulent environments. It is perhaps no coincidence given the declining fiscal resources to higher education, the demands for accountability amidst granting autonomy to the institutions, and quality in the academic programmes. Yet at the same time, the commonest pattern within institutions as they respond to these external changes has been to transfer responsibilities to the academic units premised on the nature of the university as a loosely-coupled organization comprising several academic units based on disciplines (Becher \& Trowler, 2001; Clark, 1983; Weick, 1976). Unsurprisingly, each of these subunits responds to the environment quite differently further perpetuating fragmentation. As a result, universities have sought to integrate the activities and functions of the academic units and also strengthen their links to the environment by using information technology as a key tool (Dill \& Sporn, 1995). In fact, previous studies have shown the role and relevance of information and information systems in enhancing self-regulation and hence integrated functioning of institutional management as it responds to the changing requirements of government 
(Hölttä \& Nuotio, 1995 p.14; Hölttä, 1995 p.238-239). Undoubtedly, in some European countries, universities have provided management information to government agencies and synchronized feedback has been obtained in return (Frackmann, 1994 p.33-34). Evidently, most universities have acquired integrated information systems to contribute to integration of the disparate units with the overall objective of improving efficiency and effectiveness. However, despite their valuable role in coordinating and monitoring the responses their units make to the environment, research on how to regulate the operations of middle management based on their information needs is highly needed (Creswell \& England, 1994 p.16). Moreover, most of the ITEM research in universities has focused on economic rationales of introducing ITEM, dealt with attitudinal issues concerning the users, without clear conceptual reflections (Gorr \& Hossler, 2006; McCredie, 2003; Rodrigues \& Govinda, 2003; Creswell \& England, 1994; Masland, 1985). With a few exceptions (Höltta, 1995; Hölttä \& Karjalainen, 1997) ITEM in universities has been hardly explored in terms of organizational theory. It is this perspective that this paper presents by using the organizational learning framework to explore the question how can the capacities of university ITEM in regulating the roles and functions of the academic deans with respect to academic and financial management practices be conceptualized? The next sub-section of the paper outlines the information needs of the deans with respect to their roles. This is followed by the dilemmas surrounding the work of these deans as the university seeks to harness integrative operations. Thirdly, the organizational learning framework is examined. Fourthly, discussions and conclusions are made on the possible conceptualization of the capacities of university ITEM.

\subsection{Information Needs of the Academic Deans}

Although it is not uncommon for universities to acquire ITEM systems or even establish mechanisms to determine the relevant information, the "...beginning point for most ... deans would be to conceptualize the categories of information needed and used" (Creswell \& England, 1994 p.10). Thus, it is first of all vital to explore the roles of the academic deans as a basis for understanding their information needs. Firstly, there is a faculty-oriented leadership role whose focus is on faculty morale, professional development, and promotion of university-wide faculty development activities. Essential information for this role can be found in personnel records, budget information, and policy documents and procedures. Secondly, it is possible for the dean to concentrate or emphasize the discipline or field of study. Such roles would entail keeping the discipline up-to-date by gathering information on the changing patterns in teaching, research and practice in the field. Thirdly, the dean functions as a manager. This role has a focus on support activities such as preparation of budgets, maintenance of departmental and faculty records, and assigning duties to faculty. Information required is basically on personnel records, budgeting and scheduling. Fourthly, the dean is an academic leader. In this, the strategic goals and vision are emphasized where interest is on ideas that can improve the processes within the academic unit. With regard to the hierarchical structures of the university, the deans receive information from the heads of departments, and then communicate to the central administration. Such information exchange could be related to various policies 
and procedures, alumni, students and personnel. Fifthly, academic deans may be externally oriented. It is through this that the deans stress the need to scan for external changes that affect the operations of their units, partner with various stakeholders, explore new student markets, and source for new funding opportunities. The information requirements associated with this may be met by institutional research offices on campus or external stakeholder organizations (Creswell \& England, 1994 p.13-14).

\subsection{Constraints in the Role of the Academic Deans}

The information needs and roles of the academic deans illuminate the diffusion of institutional leadership at the middle level of the organization in order to enhance responsiveness. Whereas the deans may concentrate on such managerial roles by executing the mandate of the central administration, the same deans also pay attention to "the drives of disparate academic professional groups" (Clark, 1995 p.9). Undoubtedly, the dean operates in a state of role conflict (Bray, 2008 p.692-694; Wolverton, Wolverton, \& Gmelch, 1999 p.82) and thus, to assume that deans are inclined to the managerial roles is to underestimate their disciplinary obligations of research and publishing within their parent academic units. Yet for the deans to pay exceeding attention to the academic profession is to discount the new "...image of the dean as an executive - politically astute and economically savvy" (Wolverton et al., 1999 p.81-82). The two conflicting roles certainly demand for different sets of information owing to the tensions elicited by the competing values. But still, the deans are confronted with role ambiguity. For instance, in hierarchical terms, the dean reports to the vice chancellor just as the dean receives directives from the vice chancellor or any other members of central administration. Apparently, the academic deans allocate or reallocate resources to the departments, activities and programmes within their units without any consideration of the allocation decisions of their counterparts in the same university. It is therefore certain, for example, that "...if deans receive no clear guidelines [from the central administration] about budget priorities, decisions made at the college level may seem capricious and indefensible" (Wolverton et al., 2001 p.21). Undoubtedly, vertical looseness is likely to occur in contexts where "adequate procedural safeguards" are non-existent or weak (ElKhawas, 2001 p.246; Rubin, 1979 p.213). In other words, information may not be delivered or gets distorted leaving room for multiple interpretations that are at times incongruent to acceptable standards. Certainly, the greatest challenge is how to maintain equilibrium in such contexts of conflict and ambiguities.

\section{Theoretical Learning Framework}

Organizations learn internally and also encounter internal threats to learning with implications for integrated responsiveness (Easterby-Smith \& Araujo, 1999 p.8; Kezar, 2005 p.13). Most significant is that, “... an organization learns if any of its units acquires knowledge that it recognizes as potentially useful to the organization" and "an entity learns if, through its processing of information, the range of its potential behaviors is changed" (Huber, 1991 p.89). Information is an essential 
element that enables the organization and its subunits to make responses to its external pressures in order to maintain or restore equilibrium. The disciplinary origins of organizational learning are in the Cybernetics theory. Cybernetics focuses "...on the selection of the limits that are to be placed on behavior as on the active pursuit of desired goals" (Morgan, 1997 p.99).Accordingly, the cybernetics framework suggests that "cybernetic control mechanisms" have to be in place to guide the actions of the basic units towards institutional goals and to enable the institution to respond and function as a whole as it deals with the external demands, for example, from government. The organization would establish mechanisms for self regulation on the basic assumption that "organizations [are] systems [functioning] as complexes which maintain certain essential constancies through cycles of action, error-detection, and error correction". In fact, system theorists have argued that organizational learning is evident in systems that have favorable conditions for self regulation and in instances where organizational stability is collectively pursued (Argyris \& Schön, 1978 p.325-326).

In the organizational learning framework, responsiveness of an organization is dependent on gathering and processing information about itself both internally and externally (Easterby-Smith, 1997 p.1090; Easterby-Smith \& Araujo, 1999 p.3). It is this information that provides impetus for the 'cycles of action' within the organization. These cycles of action comprise structural - social interactions through which gathering and processing information become the core processes and enablers for pursuing organizational learning. On the assumption that the environment is dynamic, and that the consequences of any interactions cannot be accurately predicted, it is necessary to establish parameters or governing values/variables within which outcomes can be ascertained or feedback on performance can be generated (Argyris \& Schön, 1978 p.18-26; Morgan, 1997 p.100; Senge, 2006 p.74-75; Senge, 2000 p.277). Indeed, due to the likely differences in responses that the organizational subunits make to external contexts, parameters or controls within which the organization operates have to be established in order to sustain equilibrium. It is against these parameters that can be in form of output or behavior that appropriate action strategies are sought, identified and deployed with the aim of achieving a certain set of desired outcomes (Argyris \& Schön, 1978). When deviations from the organizational norms occur, specifically when the actions elicit unintended or undesirable outcomes, they are detected and corrected.

As shown in Figure 1 below, following actions that may be either within or outside the limits of governing values or variables, feedback is generated. The single feedback loop "connects detected outcomes of action to organizational strategies and assumptions which are modified so as to keep organizational performance within the range set by organizational norms" (Argyris \& Schön, 1978 p.14-15). Such corrective feedback (single loop) is triggered when outcomes show low performance e.g. through built-in controls of the information system or print-outs from the information system. On the other hand, transformative feedback (double loop) is when information is used to change the values or norms themselves. Certainly management information systems are mechanisms that an organization can use to support its internal regulation and integration (Argyris \& Schön 1978 p.268-276; Easterby-Smith \& Araujo 1999 p.4). In essence, 'limits' can be established or 'control systems' 
designed or built in or installed to detect errors and take corrective actions within acceptable ranges for organizational effectiveness (Argyris and Schön 1978; Birnbaum, 1988 p.34-35; Easterby-Smith, 1997 p.1092; Hölttä, 1995 p.242-255). Obviously, deviations trigger feedback loops within the organizational processes and systems that become the basis for new actions for organizational improvement (Easterby-Smith, 1997 p.1090; Huber, 1991 p.91; Morgan, 1997 p.100). However, it has to be understood that subunits simply store new information on old information making retrieval of old information, when it is needed, difficult (Easterby-Smith, 1997 p.1093). This may constrain transformative feedback. Perhaps, it is information on external changes for instance; fiscal hardships or demands for quality or change in the interests of the stakeholders may elicit a form of information feedback that can challenge the existing values, systems and structures within the organization and its subunits (Easterby-Smith, 1997 p.1093; Hedberg et al., 1976 p.51; Hedberg, 1981 p.18-19).

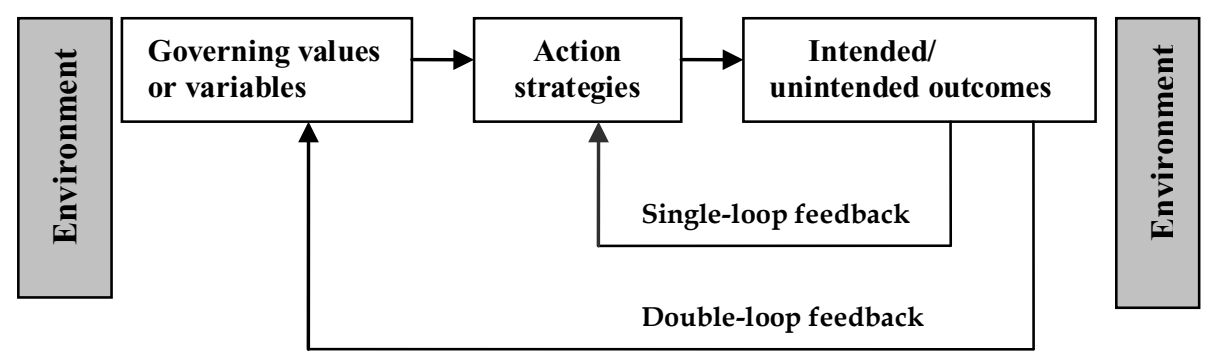

Fig. 1. Organizational learning framework

Author's compilation on the basis of Argyris and Schön (1978); Senge (2006)

By way of illustration, we can argue that, information systems have the capacity to support the accomplishment of performance targets, for instance, where there is feedback on cost and output between the subunits and central administration (Hölttä, 1995 p.248-251; Hölttä \& Nuotio, 1995 p.15). Such performance targets may be set by the central administration in terms of funds reallocation and new demands for internal accountability hence presenting new sets of information requirements for the deanship (Creswell \& England, 1994 p.8-9). As a requirement, information may have to be presented in specific formats or with certain contents to authenticate whether the output or behavior of the academic unit conforms to acceptable standards. When such required information deviates from the expected, the decision to accept is withheld until the information is corrected. A good example is the use of minutes of meetings as a valuable measure to assure that the academic and financial practices are congruent to established standards. Incidentally, some of the information that is necessary for organizational effectiveness may be withheld or not availed to the deans with the consequence of deviations in work processes or low performance of the tasks (Wolverton et al., 1999 p.82; Wolverton et al., 2001 p.21). In the use of ITEM 
systems, feedback can be generated when the limits are built into the information system or by analyzing outputs from the information system that may show significant anomalies that would elicit corrective action. All in all, the essence is to keep the organizational activities in equilibrium through self-regulative capacities of ITEM and/or using its outputs. As the external environment keeps changing, the governing values or variables may be altered in alignment with the environment. Obviously this will sanction new action strategies in form of mechanisms that will facilitate the realization of the new set targets.

\section{Discussion and Conclusions}

In this section, an attempt is made to illustrate the applications of the tenets of the organizational learning framework as shown in Figure 1. This is based on previous analysis of the perceptions of faculty deans at a Ugandan public university concerning the utilization of university ITEM systems. The ITEM system was a relational database that was an integrated vendor product that had been procured from South Africa and comprised four modules namely; the academic records information system (ARIS), finance information system (FINIS), the human resource information system (HURIS) and the library information system (MakLIBIS). The modules discussed in this section are ARIS and FINIS. Because of the peculiarities of the context, this vendor product had been quite difficult to customize to the local institutional conditions. As a result, it was found out that in addition to the structural or output controls, there were several manual or behavioral controls that augmented the regulative capacities of the ITEM systems. In the same way, two dimensions of feedback were evident. The outputs from the ITEM system elicited corrective feedback e.g. if a large percentage of students who did an examination had their grades or test scores below acceptable ranges then such an anomaly would be detected by other means such as committees because the existing ITEM system did not have the capacity to detect the error but its print outs were the basis for the detection and rectification of the error by the committee members.

With respect to financial management, the main support activity of FINIS was in the allocation of finances to the academic units. It enabled the computation of the percentages of the tuition fees that would accrue to the academic units. Financial allocations to the faculties were based on the number of privately sponsored students who had paid their tuition fees and duly registered with the faculties they belonged to. Although the remittances to the units were computed using the ITEM system, actually the university bursar had to write a cheque to the unit that would be presented in the bank in order for funds to be transferred to the account of the faculty. During the expenditure of these finances now belonging to the faculty, the ITEM system was not very helpful. In other words, its impact was mainly seen in the governing value of deciding how much was due to the faculty based on the registered students. Thus expending the resources at unit level applied other means to monitor the processes. These entailed the use of minutes of meetings of the planning and finance committee that was composed of the faculty dean, deputy deans, heads of departments and a 
student representative. Importantly, corrective feedback (single loop) was possible through the university internal auditor who verified all payments to be made by the subunits before they could be approved by the university bursar (chief finance officer). This was another example of a governing value against which errors in financial transactions would be detected and corrected.

Transformative (double loop) feedback was not directly evident in the university ITEM system. Rather informational feedback from the environment was responsible for the changes in the governing values or parameters themselves. For instance, whenever there were delays in the subventions from government to the university, the central administration responded by cutting the disbursements to the faculties or by remitting to funds to the academic units without consideration of the sharing ratios but based on the priority demands of the subunit. Similarly, when there was concern that quality was declining or new mechanisms for accreditation were being established, the information requirements for the academic units, for example as they proposed new programmes or changed existing ones triggered new mechanisms that were capable of causing modifications in the institutional strategy. This is an example of change in the values themselves as double loop feedback would envisage. This kind of change definitely requires substantial time.

Based on the perceptions from the deans that demonstrate the theoretical elements, the following conclusions can be made.

a. Information is a crucial resource in the regulation and integration of the processes of the academic units. Such information may not necessarily come from the ITEM system but, the information from the ITEM system remains highly valuable in providing the bases for decision processes. It is such information that can reduce on the ambiguities and conflicts within which the deans function. The information needs of the deans in this case generally concern management perhaps illuminating the focus of the ARIS and FINIS.

b. ITEM systems may be sophisticated but their use may only elicit a few tools for defining the controls and feedback processes. In such scenarios, other means are sought that can contribute to monitoring and ensuring that there is integration of the activities within the academic units.

c. A combination of the ITEM system and other supporting dimensions discussed illuminate the applicability of the organizational learning framework in contributing to understanding the self-regulative capacities of the university organization. What is more is that we need to pay attention to the uniqueness of the context as we deploy vendor-evolved systems.

More studies on the application of organizational theory to ITEM research are needed both in environments with advanced ITEM systems in terms of infrastructure and use, and in settings where these are not readily available. Only then can we have a clearer understanding of the capacities of ITEM and also be in position to conceptualize such capacities. There is need for more case studies and more applications of different organization theories. Organizational learning is just one of the theories. 


\section{References}

Argyris, C., Schön, D.A.: Organizational learning: A theory of action perspective. AddisonWesley Publishing Company, Reading (1978)

Becher, T., Trowler, P.: Academic tribes and territories, 2nd edn. Open University Press, London (2001)

Birnbaum, R.: How colleges work. In: The Cybernetics of Academic Organization and Leadership. Jossey-Bass, San Francisco (1988)

Bray, N.J.: Proscriptive norms for academic deans: Comparing faculty expectations across institutional and disciplinary boundaries. The Journal of Higher Education 79(6), 692-721 (2008)

Clark, B.R.: The higher education system. academic organization in cross-national perspective. University of California Press, Los Angeles (1983)

Clark, B.R.: Leadership and innovation in universities. from theory to practice. Tertiary Education and Management 1(1), 7-11 (1995)

Creswell, J.W., England, M.E.: Improving Information Resources for Academic Deans and Chairpersons. New Directions for Institutional Research 84, 5-18 (Winter 1994)

Dill, D.D., Sporn, B.: University 2001: What Will the University of the Twenty-First Century Look Like? In: Dill, D.D., Sporn, B. (eds.) Emerging Patterns of Social Demand and University Reform: Through a Glass Darkly, pp. 212-236. Pergamon/IAU Press, Oxford (1995)

Easterby-Smith, M.: Disciplines of organizational learning: Contributions and critiques. Human Relations 50(9), 1085-1113 (1997)

Easterby-Smith, M., Araujo, L.: Organizational learning: Current debates and opportunities. In: Easterby-Smith, M., Burgoyne, J., Araujo, L. (eds.) Organizational Learning and the Learning Organization. Developments in Theory and Practice, pp. 1-21. Sage Publications, London (1999)

El-Khawas, E.: Today's universities: Responsive, resilient or rigid? Higher Education Policy 41(241), 248 (2001)

Frackmann, E.: Administration. In: Bull, G.M., Dallinga-Hunter, C., Epelboin, Y., Frackmann, E., Jennings, D. (eds.) Information Technology. Issues for Higher Education Management, pp. 28-38. Jessica Kingsley Publishers, London (1994)

Gorr, W., Hossler, D.: Why all the fuss about information systems? or information systems as golden anchors in higher education. New Directions for Higher Education (136), 7-20 (2006)

Hedberg, B.: How organizations learn and unlearn. In: Nystrom, P.C., Starbuck, W.H. (eds.) Handbook of Organizational Design, Adapting Organizations to Their Environments, vol. 1, pp. 3-27. Oxford University Press, New York (1981)

Hedberg, B.L.T., Nystrom, P.C., Starbuck, W.H.: Camping on seesaws: Prescriptions for a selfdesigning organization. Administrative Science Quarterly 21(1), 41-65 (1976)

Hölttä, S.: Towards the self-regulative university. University of Joensuu. University of Joensuu Publication in Social Sciences 23 (1995)

Hölttä, S., Karjalainen, K.: Cybernetic institutional management theory and practice: A system of flexible workload for university teachers. Tertiary Education and Management 3(3), 229-236 (1997)

Hölttä, S., Nuotio, J.: Academic leadership in a self-regulative environment. A challenge for Finnish universities. Tertiary Education and Management 1(1), 12-20 (1995)

Huber, G.P.: Organizational learning: The contributing processes and the literatures. Organization Science 2(1), 88-115 (1991) 
Kezar, A.: What campuses need to know about organizational learning and the learning organization. New Directions for Higher Education 131, 7-22 (2005)

Masland, A.T.: Administrative computing in higher education. In: Smart, J.C. (ed.) Higher Education: Handbook of Theory and Research, pp. 173-212. Agathon Press, New York (1985)

McCredie, J.: Does IT matter to higher education? Educause Review, 15-22 (2003)

Morgan, G.: Images of organization, 2nd edn. Sage Publications, Thousand Oaks (1997)

Rodrigues, A.J., Govinda, S.: Towards an integrated management information system: A case of the University of Mauritius. Information Technology for Development 10, 41-56 (2003)

Rubin, I.S.: Retrenchment, loose structure and adaptability in the university. Sociology of Education 52, 211-222 (1979)

Senge, P.: The academy as learning community: Contradiction in terms or realizable future. In: Lucas, A.F., Associates (eds.) Leading academic change: Essential roles for department chairs, pp. 275-300. Jossey-Bass, San Francisco (2000)

Senge, P.M.: The fifth discipline. the art \& practice of the learning organisation. Random House Business Books, London (2006)

Weick, E.K.: Educational organizations as loosely coupled systems. Administrative Science Quarterly 21(1), 1-19 (1976)

Wolverton, M., Gmelch, W.H., Montez, J., Nies, C.T.: The changing nature of the academic deanship. Jossey-Bass/ ASHE-ERIC, San Francisco (2001)

Wolverton, M., Wolverton, M.L., Gmelch, W.H.: The impact of role conflict and ambiguity on academic deans. The Journal of Higher Education 70(1), 80-106 (1999) 